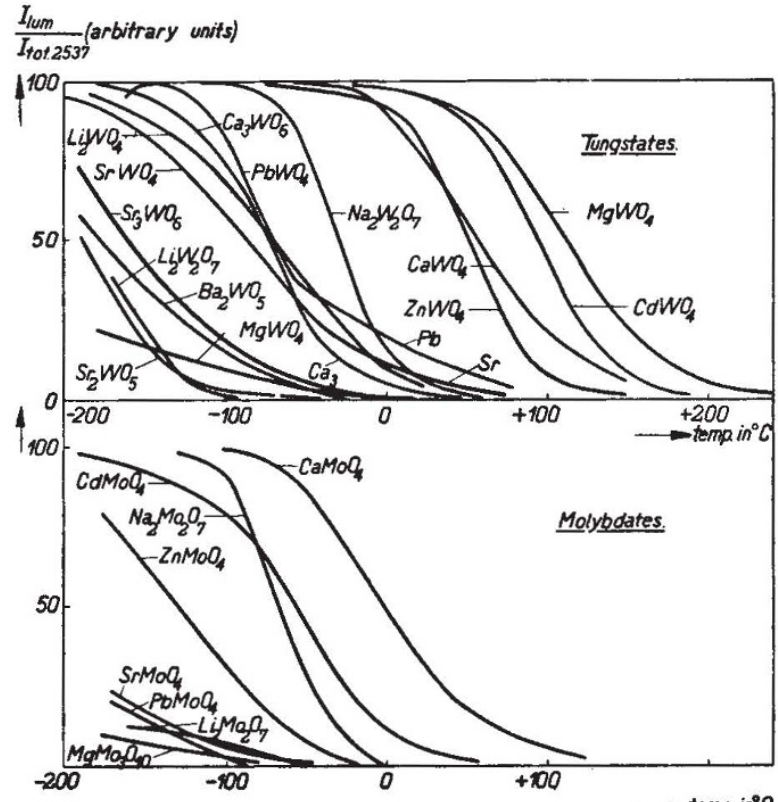

Temp.in TEMPERATURE-DEPENDENCE OF THE FLUORESCRNCE OF TUNGSTATES $\triangle N D$ MOLYBDATES FOR EXCITATION BY $\lambda 2537$ A. (MAXIMA MAGNESIUM TUNGSTATE THAT IS QUENCHED AT LOW TEMPERATORES IS THE $a$-FORM)

Nearly all substances investigated show fluorescence at a low temperature upon excitation by $\lambda 2537 \mathrm{~A}$. (see graph). The temperature-range in which quenching occurs is different, not only for compounds of different composition, but also for the same compound in different modifications $(\alpha$ - and $\beta$-magnesium tungstate). For the few tungstates for which no luminescence was found, the quenching range is probably situated beyond $-180^{\circ} \mathrm{C}$., so that fluorescence may be expected at extremely low temperatures. The quenching-ranges of tungstates are, on the whole, at higher temperatures than those of the molybdates. This explains why many more tungstates than molybdates are known to show luminescence.

A more complete report of our investigations, including measurements of absorption and fluorescence spectra, is to be published elsewhere ${ }^{2}$.

Natuurkundig Laboratorium der F. A. KRöger

N. V. Philips' Gloeilampenfabrieken, Eindhoven.

Feb. 21.

1 Hüniger, cited by Birus, K., Ergeb. Exakt. Naturw., 20, 221 (1942), Hill, C. G. A., Trans. Farad. Soc., 42, 666 (1946).

2 Kröger, F. A., "Some Aspects of the Luminescence of Solids" (Elsevier Publishing Co., Amsterdam and New York, 1947), in the press.

\section{Gas Discharge in Air of Atmospheric Pressure at Very Low Voltage}

Ir has been observed that a potential difference of as little as $15 \mathrm{~V}$. applied between two semi-conductors in contact with each other, or alternatively, of a semi-conductor in contact with a metal, may sustain a gas discharge in air of atmospheric pressure.

The semi-conductors used were grains of pale green carborundum, selected for paleness from commercial No. 8 mesh samples. The grains were either stuck with solder into metal holders, or laid on a hardened and polished steel block and a second similar block laid on top of the grain. The potential was taken from the sliding contact of a low-impedance potentiometer across D.C. mains and measured by means of an ordinary voltmeter.

The gas discharge was of a pale bluish-mauve colour, and if viewed through a low-power microscope was seen to consist of streamers from grain to grain (or grain to steel block) near the point of contact. The streamers were several microns long.

The phenomenon could not be observed in every case. The potential range at which it would occur is from less than $15 \mathrm{~V}$., but more than $13 \mathrm{~V}$. to about $50 \mathrm{~V}$. At higher potentials the contact area would as likely as not become incandescent and, therefore, so highly conductive that equipotential surfaces in the crystal would move outwards, bringing the areas of the crystal where the potential difference across the gap reaches $15 \mathrm{~V}$. into regions where the air-gap becomes too wide.

A phenomenon like this was expected to occur only in the immediate neighbourhood of the contact, that is, where the air-gap was comparable with the mean free path of gas molecules. Where in fact it occurs, the path along the streamer contains many hundred mean free paths, and it is therefore believed that radiation from streamer to streamer plays an essentia] part in the excitation mechanism.

Bay and Szigeti ${ }^{1}$ described luminous phenomena on carborundum crystals. Similar phenomena were also observed by me. They are apparently due to incandescence at the point of contact and occur if the current is allowed to build up to values in excess of those at which gas discharges can occur. Light travelling from the incandescent zone inside the crystal emerges from its whole surface and gives the appearance of the whole crystal being luminous. As the light is due to the incandescence of a substance which disintegrates below $2,000^{\circ} \mathrm{K}$., and which radiates rather like a black body, it is originally of a yellow tinge. After transmission through a more or less coloured crystal, it emerges filtered sometimes as a pure white and sometimes as a brilliant yellow. The bluish-mauve colour of the gas-discharge described above has never been observed to emerge from the mass of the crystal. There is also no lowvoltage limit for sustaining this mass glow once it has been initiated.

My observations are now some years old. Pressure of other work has since, and will presumably in the future, prevent my following the matter up further.

116 Regal Way,

Preston Hill, Harrow, Middx.

${ }^{1}$ U.S. Patent No. 2,254,957, September 2, 1941, and an earlier Hungarian patent of October 23, 1939

\section{Total Emission Damping in Diodes}

A FEw months ago, C. N. Smyth ${ }^{1}$ published preliminary results on a new source of energy loss in space-charge-limited diodes at high frequencies. This energy loss was due to the space-charge between the electrodes, and hence it was called 'total emission damping'; it is a transit time effect occurring at ultra-high frequencies only. The same effect was observed a few years ago at this Laboratory at about. $100 \mathrm{Mc}$. After reading Mr. Smyth's communication we took up this subject again.

We carried out measurements at $5.8 \mathrm{~m}$. wavelength on a diode having an emitting cathode area 